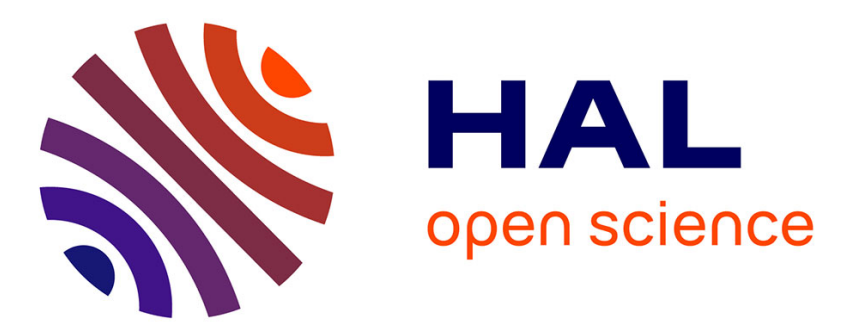

\title{
Ranking of wetting-drying, plant, and fauna factors involved in the structure dynamics of a young constructed Technosol
}

Nouhou Salifou Jangorzo, Françoise Watteau, Christophe Schwartz

\section{To cite this version:}

Nouhou Salifou Jangorzo, Françoise Watteau, Christophe Schwartz. Ranking of wetting-drying, plant, and fauna factors involved in the structure dynamics of a young constructed Technosol. Journal of Soils and Sediments, 2018, 18 (9), pp.2995-3004. 10.1007/s11368-018-1968-5 . hal-02019971

\section{HAL Id: hal-02019971 \\ https://hal.science/hal-02019971}

Submitted on 14 Feb 2019

HAL is a multi-disciplinary open access archive for the deposit and dissemination of scientific research documents, whether they are published or not. The documents may come from teaching and research institutions in France or abroad, or from public or private research centers.
L'archive ouverte pluridisciplinaire HAL, est destinée au dépôt et à la diffusion de documents scientifiques de niveau recherche, publiés ou non, émanant des établissements d'enseignement et de recherche français ou étrangers, des laboratoires publics ou privés. 


\title{
Ranking of wetting-drying, plant, and fauna factors involved in the structure dynamics of a young constructed Technosol
}

\author{
Nouhou Salifou Jangorzo ${ }^{1,2} \cdot$ Françoise Watteau ${ }^{2} \cdot$ Christophe Schwartz $^{2}$ (D)
}

Received: 20 July 2017 / Accepted: 4 March 2018

(C) Springer-Verlag GmbH Germany, part of Springer Nature 2018

\begin{abstract}
Purpose Dynamical in situ observation of biological and climatic structuring factors involved in pedogenesis has not previously been possible in a way that would consider the early stages of pedogenesis. If studies have explored the effect of pedogenetic factors on soil structure, none have succeeded in ranking them in view of the intensity of their effects. We propose a novel approach for describing the aggregation process for a constructed Technosol obtained from a process of pedological engineering. Materials and methods We focus on agents including plants, macrofauna, and water, and we use (i) a dynamic in situ observation and (ii) the quantification of the evolution of selected descriptors of pores and aggregates. They are quantified from highresolution images obtained with the Soilinsight ${ }^{\circledR}$ device. Associating those images with each other, movies of interactions between soil and organisms over a 14-month non-destructive soil evolution experiment are made.

Results and discussion Agents influencing aggregation - plant roots, earthworms, and water — can be ranked according to their impact on soil structure. During the studied period of evolution, wetting-drying cycles are the first to operate. The intensity of their action on soil structure is dominant at the very first stages of pedogenesis. Despite this ranking of agents, over the long term, plants and earthworms have a more intense effect on soil structure than wetting-drying cycles.

Conclusions The method applied to observe and quantify soil structure dynamics is thus proposed as a helpful approach to modeling other processes involved in soil functioning and evolution in relation to their ability to fulfill ecosystem services.
\end{abstract}

Keywords Drilosphere $\cdot$ Image analysis $\cdot$ Pedological engineering $\cdot$ Rhizosphere $\cdot$ Soil function $\cdot$ Soil structure modeling

\section{Introduction}

There is a need to better understand the functioning and evolution of constructed Technosols in relation to their ability to fulfill functions and to provide ecosystem services. At the same time, constructed Technosols (IUSS Working Group WRB 2006) are suitable candidates to study early pedogenesis as a soil engineering process controls their initial composition

Responsible editor: Richard K. Shaw

Electronic supplementary material The online version of this article (https://doi.org/10.1007/s11368-018-1968-5) contains supplementary material, which is available to authorized users.

Christophe Schwartz

christophe.schwartz@univ-lorraine.fr

1 Université Dan Dicko Dankoulodo, BP 465, Maradi, Niger

2 Laboratoire Sols et Environnement, Université de Lorraine, Inra, F-54000 Nancy, France
(Séré et al. 2010). Among pedogenetic processes, aggregation is a dynamic process linked with major soil functions as organic carbon stabilization, nutrient cycling, and soil structure stability (Niewczas and Witkowka-Walczak 2005).

Except X-ray computed tomography approaches (Taina et al. 2008), standard sampling methods generally lack precision in accounting for aggregation dynamics, since sampling techniques involve disturbance and exportation of part of the system, thereby interrupting the soil evolution process (Jangorzo et al. 2014). One of the most exciting and highly anticipated developments for soil scientists has therefore been the ability to firstly observe in situ how major pedogenic factors act in creating soil structure and then to record this information for a better understanding, description, quantification, and modeling of soil functions, especially for Technosols (Leguédois et al. 2016). Many factors of pedogenesis (e.g., climate, bedrock, topography, biological activity) and associated agents are involved in the formation of organo-mineral aggregates in soil. Major agents among them are (i) soil fauna, (ii) plant roots, (iii) microorganisms, (iv) inorganic binding 
agents, and (v) environmental variables (e.g., temperature, humidity) (Six et al. 2004). Wetting-drying cycles, as environmental agents, are known to influence the formation of stable aggregates (Amezketa 1999). Their effect on soil properties (e.g., porosity) depends for example on whether there is swelling clay in the soil or not. Aggregates are described to be more stable when the clay does not swell (Singer 1992; Attou and Bruand 1998; Denef et al. 2001).

Plant roots contribute to the stability of aggregates by penetrating soil, modifying the water regime in the rhizosphere, secreting exudates, providing organic matter degraded by microorganisms, and enmeshing soil particles (Angers and Caron 1998; Six et al. 2004). Most of the studies concerning the effect of roots on the rhizospheric soil have focused on the compacting effect on root-aggregates in comparison to the bulk soil (Bruand et al. 1996; Milleret et al. 2009) without taking into account the variability of the porosity. Furthermore, it has been admitted that a sharp boundary cannot be drawn between rhizospheric and bulk soil. However, even if the physical extent of the active rhizosphere is not easily defined, it is expected to extend only a few millimeters from the root surface, depending on plant species (Hawkes et al. 2007), and to be the volume of soil directly influenced by the root activity (Hinsinger et al. 2009). Also, the spatial distribution of roots in the soil system, driven by geotropism, is plant-species or plant-variety dependent.

Besides, the activity of roots and earthworms, as soil fauna, contributes to the formation of stable aggregates by burrowing and casting (Brown et al. 2000; Pey et al. 2013, 2014) and to the improvement of soil porosity (Bottinelli et al. 2010). As for the rhizosphere, the extent of the drilosphere is uncertain as it depends on the earthworm species (Andriuzzi et al. 2013). If the drilosphere is traditionally assumed to extend to $2 \mathrm{~mm}$ (Bouché 1975), some authors (Andriuzzi et al. 2013) consider that it goes further. The difficulty in determining the extent of the drilosphere comes from its definition, which takes into consideration the earthworm populations and the complete soil volume, as well as microbial and invertebrate populations affected by their activities (Lavelle 1988). Depending on their ecological category, earthworms preferentially colonize different pedosphere locations. Anecic species are known to burrow vertically and deeper in the soil, whereas epigeic species preferentially feed and stay in the upper soil horizons (Andriuzzi et al. 2013; Brown et al. 2000). The behavior of plant roots and earthworms has been described in a previous work (Jangorzo et al. 2015), thanks to a video obtained with the Soilinsight ${ }^{\circledR}$ device (see Electronic Supplementary Material). It has also been highlighted that earthworms created three kinds of burrows - vertical, skew, and horizontal — preferentially along plant roots. The intensity of burrowing contributes to soil structure formation. In addition, it has been demonstrated that the preferential water flow along vertical roots contributes to creating voids and that a dense root network is preferable for enmeshing soil particles, thereby leading to the development of isolated macro-aggregates (Jangorzo et al. 2015).

All these factors (and related agents) contribute independently or in association to improving soil structure, but their actions have never been hierarchized. Many organisms cohabit in the soil and generate spheres (e.g., rhizosphere and drilosphere) and the existence of one could be conditioned by the activity of another (Bell et al. 2015). This behavior guided by the cooperation between plant roots and earthworms has been demonstrated to contribute to creating stable macro-aggregates (Zangerlé et al. 2011). The absence of a sharp boundary between rhizo- and drilosphere enhances the difficulty to study the soil-organism system (Brown et al. 2000). For example, knowing that earthworms burrow preferentially along plant roots (Jangorzo et al. 2015), it is impossible to separate the rhizosphere from the drilosphere. Studies concerning the quantification of the influence of this synergy on the evolution of soil structure according to the soil depth are scarce.

The aim of this paper is then, for a young constructed Technosol, (i) to hierarchize three main pedogenic agents (water, plant roots, earthworms) according to their influence on soil structure, through an in situ dynamic observation and quantification and (ii) to quantify the synergy between roots and earthworms in creating soil porosity according to the soil depth. Here we hypothesized that biological agents are major drivers of soil structuring and due to their ecological category, the effect of earthworms is soil-depth dependent.

\section{Materials and methods}

\subsection{In situ observation of soil dynamics}

Soilinsight ${ }^{\circledR}$ is a recently developed device (Jangorzo et al. 2015) to observe a soil both in situ and dynamically. It was built to automatically generate images of soil contained in mesocosms, over a relatively long period of 14 months. Mesocosms are boxes made of opaque polymethyl methacrylate of the following size: $35-\mathrm{cm}$ length, $21-\mathrm{cm}$ width, and 5$\mathrm{cm}$ depth. One face of the mesocosm consists in an antireflexive glass allowing us to observe the soil surface and acquire images. The system is programmed to capture one image every $2 \mathrm{~h}$ in .tif format at a resolution of $1200 \mathrm{dpi}$.

We used this device to observe a constructed Technosol, under the influence of three major aggregation factors: soil fauna, plant roots, and environmental variables with a focus on water. A wetting (100\% field capacity)-drying ( $20 \%$ field capacity) cycle, as a proxy for climatic conditions, Lupinus albus as the plant, and Lumbricus castaneus as the soil fauna were used as agents in a 14-month-long experiment, including a control without plant and fauna. Using these factors, we 
constituted three modalities: a wetting-drying cycle (WD), plant $(\mathrm{P})$, and plant-fauna $(\mathrm{PF})$. The results of the latter $(\mathrm{PF})$ were previously published in a paper which focused in greater depth, on the presentation of an innovative way of monitoring and quantifying the impact of pedogenic factors on the functioning and evolution of Technosols (Jangorzo et al. 2015). In this previous article, only one modality was selected (PF) to make this demonstration. That being acquired, the present paper is now dedicated to compare 3 modalities and a control (C) including PF (formerly published) and WD and P (as additional results), in order to rank their influence on soil structure dynamics. With high-resolution images (1200 dpi) generated every $2 \mathrm{~h}$ for 268 days, we photographed the dynamic evolution of soil structure. Porosity and aggregation were quantified according to standard image analysis methods. Steps of "acquisition," "filtering," "segmentation," "gray scale transformation," "thresholding," and "analysis" were performed. Three porosity parameters indicative for pore function were quantified: surface area (A), shape factor (Sf), and equivalent diameter $(\mathrm{Ed})$. The total surface area of aggregates was also determined. The choice of images and the protocol of image analysis are described in Jangorzo et al. (2013, 2014).

\subsection{Composition of the constructed Technosol}

\subsubsection{Characteristics of the constructed Technosol}

Three 2-mm-sieved materials were used to construct the Technosol: (i) green waste compost (GWC) obtained from tree pruning and shearing residues from an urban area, (ii) thermally treated industrial soil (TIS), and (iii) paper-mill sludge (PS), with the characteristics described in Table 1. These materials and the process of Technosol construction have been widely described (Séré et al. 2008). The "relative moisture" (expressed by the ratio $100 \mathrm{Ha} / \mathrm{He}$, where $\mathrm{Ha}$ is the absolute moisture of the soil and $\mathrm{He}$, the absolute moisture for a $\mathrm{pF}$ value of 2.7) of TIS (32.9\%) and PS (18\%) was determined according to the method described by Baize (2000). Then, we prepared a mixture of TIS-PS in a $2 / 3-1 / 3$ mass ratio (Jangorzo et al. 2015).

\subsubsection{Soil conditioning}

Based on the methods of Mathieu et al. (1998), the moisture at field capacity $(39.4 \%)$ and wilting point $(20.9 \%)$ for the selected TIS-PS mixture were determined. Then, the materials were air-dried, crushed, and sieved at $500 \mu \mathrm{m}$ in order to maximize the aggregate formation process. To eliminate the meso- and macrofauna, the air-dried soil samples were frozen at $-20{ }^{\circ} \mathrm{C}(72 \mathrm{~h})$, thawed at $+20{ }^{\circ} \mathrm{C}(72 \mathrm{~h})$, and heated at $60{ }^{\circ} \mathrm{C}(72 \mathrm{~h})$, as a combination of Huhta et al. (1989) and
Table 1 Main physico-chemical characteristics of the parent materials of the Technosol and of the mixture of the organo-mineral layer (GWC, green waste compost; PS, paper-mill sludge; TIS, treated industrial soil; PS/TIS, mixture made with TIS-PS in 2/3-1/3 mass ratio; OM, organic matter; CEC, cation exchange capacity; nd, non-determined)

\begin{tabular}{lllll}
\hline Parameters & GWC & PS & TIS & PS/TIS \\
\hline Clay $\left(\mathrm{g} \mathrm{kg}^{-1}\right)$ & nd & nd & 49 & 151 \\
$\mathrm{OM}\left(\mathrm{g} \mathrm{kg}^{-1}\right)$ & 376 & 251 & 94 & 137 \\
$\mathrm{CEC}\left(\mathrm{cmolc} \mathrm{kg}^{-1}\right)$ & 42.3 & 4.6 & 6.7 & 7.3 \\
$\mathrm{pH}$ & 8.6 & 7.9 & 9.0 & 8.4 \\
\hline
\end{tabular}

Ernst et al. (2008) methods. These operations were repeated twice.

Three horizons of distinct materials were deposited in the mesocosms from the bottom to the top, in order to reproduce a constructed Technosol: (1) a layer of gravel $(500 \mathrm{~g}$, length $3.1 \mathrm{~cm}$ ) retained by a fine mesh, to ensure a good drainage; (2) $2 \mathrm{~kg}$ of soil mixture sieved at $500 \mu \mathrm{m}$ (length $20.4 \mathrm{~cm}$; bulk density 1.17 g.cm ${ }^{-3}$ ); (3) a small layer of compost ( $100 \mathrm{~g}$, length $3.7 \mathrm{~cm}$ ) also sieved at $500 \mu \mathrm{m}$, available as food for earthworms. The different materials deposited in horizons were taken from a previously homogenized batch and were moistened for $24 \mathrm{~h}$ by capillarity by plunging the mesocosm in distilled water to $2 / 3$ of its height. After saturation, the mesocosms were weighed to determine the water content at field capacity. During the experiment, the system was irrigated to maintain a moisture content between 63 and $79 \%$ of field capacity.

\subsection{Biological aggregation factors}

We used a Fabaceae, namely Lupinus albus L., 1753 as lupin better contributes to the formation of stable aggregates than other leguminous like white clover (Haynes and Beare 1997). Lupin seeds were set to germinate between two sheets of wet filter paper in Petri dishes. On the first day of experiment (D0), 4-day-old lupin seedlings were planted per mesocosm. Ten days later, the same operation was repeated in order to replace the plants that did not grow.

As the macrofauna agent, we chose the earthworm Lumbricus castaneus (Savigny 1826), the same species used in the GISFI experimental station in previous experiments. Moreover, parent materials used to build the soil column were collected from this site. The earthworms were hand-sorted at the field where the Technosol had been constructed (Séré et al. 2008). Before their introduction into the mesocosms, the earthworms were cleaned, delicately dried, and weighed. They also had been adapted to the same experimental conditions accustoming them to the soil mixture for 7 days. For an experiment where earthworms are concerned, Fründ et al. (2010) recommend considering their density in natural conditions. Nevertheless, there are few case studies 
concerning the density of earthworms in constructed soils, especially in the early stages of their evolution (Pey 2010). However, according to a study by Smetak et al. (2007) carried out on an Anthrosol, the density of earthworms in a young soil is low (26 earthworms $/ \mathrm{m}^{-2}$ ) compared to old soils (up to 437 earthworms $/ \mathrm{m}^{-2}$ ). Nevertheless, Lowe and Butt (2005) estimated that the optimal density for an experiment with Lumbricus Terrestris Linnaeus, 1758, in mesocosms of $2 \mathrm{~L}$ is between 3 and 5 adults. In our study and to generate homogeneous experimental conditions, we introduced six previously weighed epigeic, L. castaneus, 70 days after the beginning of the experiment, when the plants were installed. This density is chosen based on considering the volume of our mesocosms $(2.9 \mathrm{~L})$ greater than that of Lowe and Butt. However, without reference on $L$. castaneus and knowing that $L$. terrestris is a bigger worm, we introduced the maximum number of six to maximize the effect.

\subsection{Measuring the cooperation between roots and earthworms}

To confirm the synergy between roots and earthworms in creating soil structure, we quantified and compared three porosity parameters by image analysis (area, A; equivalent diameter, $\mathrm{Ed}$; and shape factor, $\mathrm{Sf}$ ) in the rhizosphere and drilosphere (planted, with and without earthworms). Based on different propositions in the literature, we considered the rhizosphere to be $12.5 \mathrm{~mm}$ to either side of a root. Therefore at the end of the experiment, we sampled, following mean roots, three rhizosphere images $25 \times 50 \mathrm{~mm}$ in size, at different depths of the mesocosm - top, middle, bottom - in P (plant) and PF (plantfauna) modalities (Fig. 1a, b).

At each depth, we sampled three images on the three replicates of plant and plant-fauna modalities. All images were analyzed with Visilog, according to the protocols developed previously and described by Jangorzo et al. $(2013,2014)$ and allowing to quantify porosity and aggregation descriptors.

\subsection{Experimental conditions}

The experiment was carried out in a controlled environment, i.e., a $16-\mathrm{m}^{3}$ growth chamber. We used a 16 -h day length with a constant temperature of $20{ }^{\circ} \mathrm{C}$ and a relative moisture of $50 \%$. The experiment was randomized in two blocks. Four replicates of P (plant) modality, PF (plant + fauna) modality, $\mathrm{C}$ modality (control without plants nor earthworms), and WD cycle modality (wetting (100\% field capacity)-drying (20\% field capacity) as climatic conditions were prepared. Soils of modalities $\mathrm{P}, \mathrm{PF}$, and $\mathrm{C}$ were maintained at a moisture level of $80 \%$ of field capacity. Three replicates of each modality were dedicated to processing quantification and one to the monitoring of soil moisture evolution. Mesocosms were set up on a tilting table with a slope of $40^{\circ}$ in order to make roots and earthworms visible on the glazed surface, thanks to geotropism.

\subsection{Statistical analysis}

Analysis of variance (ANOVA) and non-parametric statistical tests (Mann-Whitney $U$ test) were performed with KaleidaGraph software to study both the effect of the soil depth on the evolution of soil structure and to compare the effects of pedogenic agents at the threshold of 5\%. Before the analysis, the normality distribution verified on data consisted in the quantified soil structure parameters (surface, equivalent diameter, shape factor, eccentricity, and distance).

\section{Three results}

\subsection{Observation of the soil dynamics}

The observation of the video (see Electronic Supplementary Material) helped to describe the main phenomena related to soil structure dynamics. For the PF modality, the root growth in comparison to that of the control, as well as the behavior of earthworms, were previously described by Jangorzo et al. (2015). Results showed that plant roots preferentially used cracks when growing and their effect is age dependent. Earthworms preferentially burrowed along plant roots and their intensity activity was predominately located at the surface and when soil was moistened. In the WD cycle modality, the soil dried with time, progressively from the top to the bottom of the mesocosm. The consequence was the apparition of three kinds of fissures or cracks: horizontal, skew, and vertical ones. These fissures stayed opened until the first wetting (first cycle). When the soil was wetted, the cracks shrunk but conserved their shape. Indeed, when water flowed, it transported soil particles through fissures according to the intensity. The consequence of this was the reduction of void diameters when particles filled the fissures. When the system dried, the existing cracks re-opened but never recovered their initial volume.

In the presence of plants (P modality), as soon as they germinated, roots appeared and created porosity, even if they did not pass through existing macroporosity. Primary and secondary roots were respectively mainly vertical and lateral. Vertical roots provided a preferential flow path for water. The repeated flow of water along the roots generated a leaching of soil particles and consequently pores. This was best demonstrated when the roots were aging. Indeed, when the roots grew older, they shrank, thus revealing some voids (pores). Sixty days after the beginning of the experiment, some nodes appeared and at D170, no further root growth was visualized. 


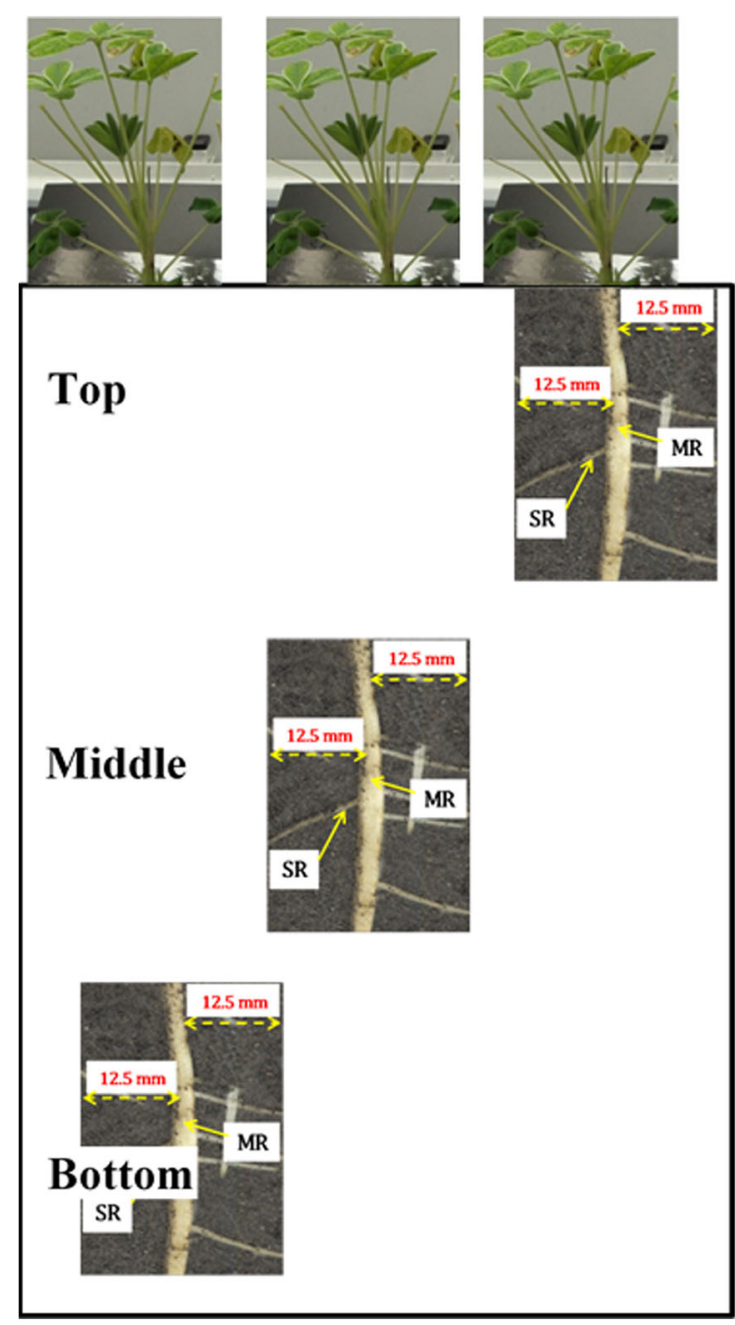

a

Fig. 1 Sampling method in studying the cooperation between plant roots and earthworms. a Schematic position of image samples according to soil depth. b Example of sample realized on an image generated at day D19

\subsection{Quantification of soil structure parameters}

\subsubsection{Defining a model of pedogenic agents hierarchy}

Results of quantified pore $(>25 \mu \mathrm{m})$ and aggregate $(>50 \mu \mathrm{m})$ parameters at main dates (D0, D52, D95, D147, D211, and D268) showed that at the beginning of the experiment (D0) surfaces of aggregates and porosity did not differ between modalities (ANOVA, $p=0.65$ and $p=0.69$ respectively) (Fig. 2). In the control, porosity increased with time until the soil was irrigated, then it durably decreased throughout the experiment (Fig. 3a). In parallel, the percentage of aggregates was constant with time (Fig. 3b). We observed the same behavior in the WD modality but with greater amplitude. Porosity and number of aggregates in WD increased then decreased, staying quite systematically higher than those in the control.

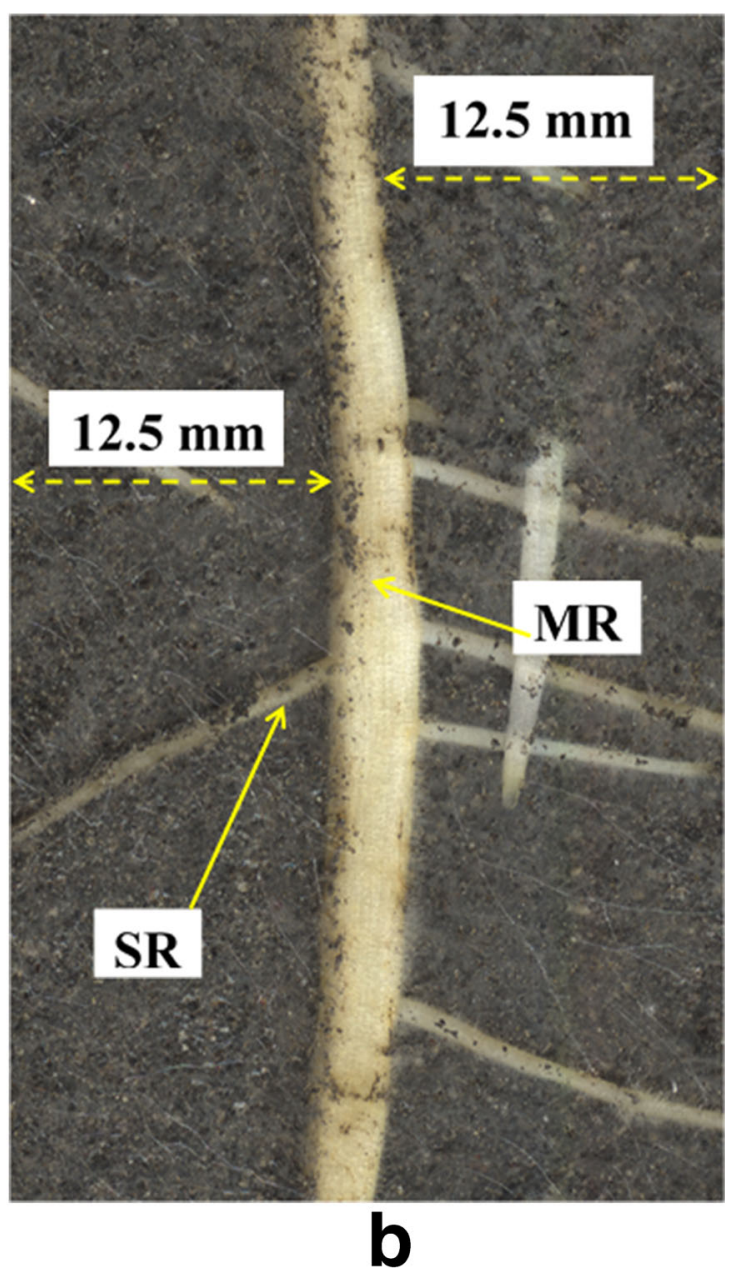

on PF modality (plant and fauna) in the middle of the mesocosm. MR, mean root; SR, secondary root

Plant roots and earthworms induced similar changes in the soil structure by creating pores and aggregates in the $\mathrm{P}$ and $\mathrm{PF}$ modalities. After an initial increase, we observed a decrease in soil structure formation (indicated by the surface of aggregates and pores). Then this began to increase again, to a constantly greater extent in the PF modality. The evolution of surface of aggregates was more irregular than that of porosity, whether in the presence of plant or both plant and earthworms (Fig. 3).

From D0 to D52, porosity increased significantly in all modalities (ANOVA, $p<0.0001$ ), but the greatest increase was observed in the WD modality (Table 2, a). This was significantly lower in P modality than in C and WD (MannWhitney $p=0.0002$ and $p<0.0001$ respectively). From D52 to D95, porosity significantly decreased in WD (MannWhitney $p=0.04$ ) and significantly increased in P (MannWhitney $p<0.0001$ ). Despite this increase, porosity in $\mathrm{P}$ modality remained significantly lower than that in $\mathrm{C}$ and $\mathrm{WD}$ 


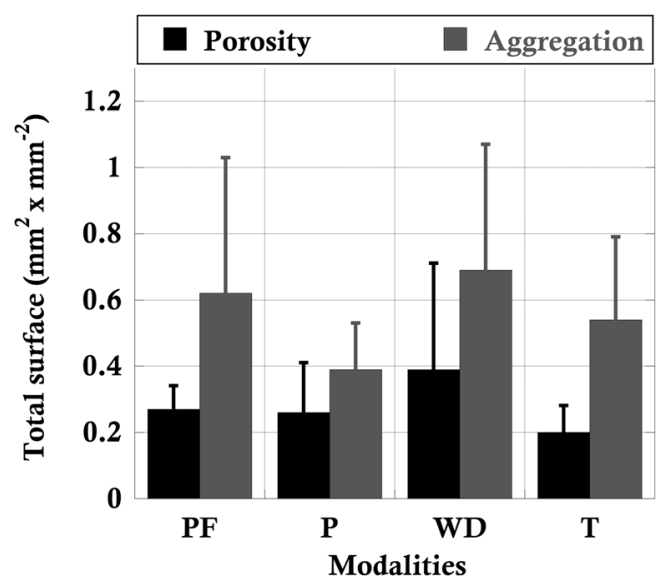

Fig. 2 Comparison of surface percentage of soil porosity and aggregation at D0 according to the modalities. PF, plant and fauna; P, plant; WD, wetting-drying cycle; $\mathrm{C}$, control. Values followed by different letters in a same line show a significant difference between modalities at a threshold of 5\% (date were obtained from three replicates of each modality at each given date)
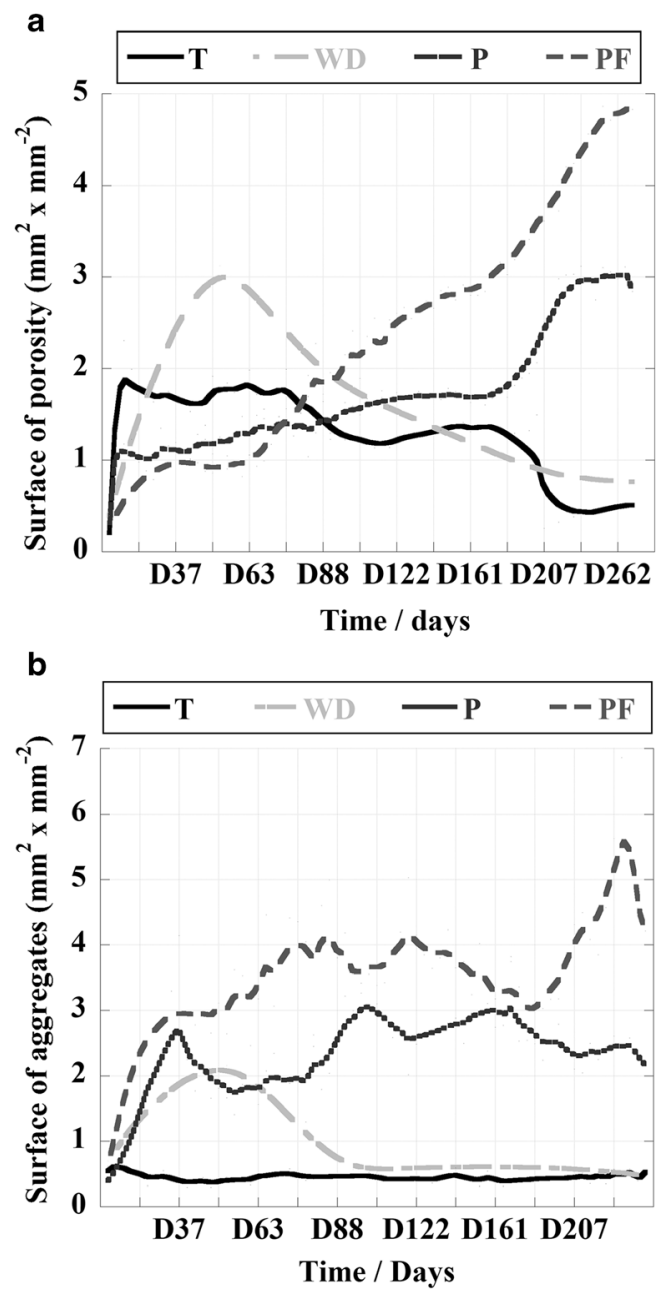

Fig. 3 Dynamics of soil porosity (a) and aggregation (b) according to the modalities. C, control; WD, wetting-drying cycle; $\mathrm{P}$, plant; $\mathrm{PF}$, plant and fauna
Table 2 Mean and standard deviation $( \pm$ ) comparing the effects of aggregation agents on pore surfaces (a) and aggregate surfaces (b) of a constructed Technosol in percentage of the total surface of the mesocosm and according to time. $C$, control; $W D$, wetting-drying; $P$, plant; $P F$, plant and fauna

\begin{tabular}{lllll}
\hline & C & WD & P & PF \\
\hline a & & & & \\
D0 & $0.54 \pm 0.14$ & $0.69 \pm 0.38$ & $0.39 \pm 0.14$ & $0.62 \pm 0.41$ \\
D52 & $0.46 \pm 0.07$ & $2.16 \pm 1.23^{*}$ & $2.34 \pm 0.90^{*}$ & $2.90 \pm 0.18^{*}$ \\
D95 & $0.45 \pm 0.07$ & $0.57 \pm 0.22$ & $2.07 \pm 0.52^{*}$ & $3.73 \pm 0.77^{* *}$ \\
147 & $0.45 \pm 0.07$ & $0.60 \pm 0.31$ & $2.80 \pm 0.38^{*}$ & $3.75 \pm 0.44^{* *}$ \\
D211 & $0.41 \pm 0.07$ & $0.57 \pm 0.42$ & $2.68 \pm 0.58^{*}$ & $3.14 \pm 0.49^{* *}$ \\
D268 & $0.48 \pm 0.05$ & $0.47 \pm 0.42$ & $2.34 \pm 0.18^{*}$ & $4.87 \pm 0.96^{* *}$ \\
b & & & & \\
D0 & $0.19 \pm 0.08$ & $0.39 \pm 0.32$ & $0.26 \pm 0.15$ & $0.27 \pm 0.07$ \\
D52 & $1.78 \pm 0.29$ & $3.12 \pm 0.77^{*}$ & $1.12 \pm 0.17$ & $0.82 \pm 0.25$ \\
D95 & $1.68 \pm 0.22$ & $1.85 \pm 0.54$ & $1.34 \pm 0.20$ & $1.70 \pm 0.32$ \\
D147 & $1.25 \pm 0.09$ & $1.29 \pm 0.13$ & $1.66 \pm 0.07^{*}$ & $2.46 \pm 0.40^{* *}$ \\
D211 & $1.37 \pm 0.07$ & $0.85 \pm 0.24$ & $1.80 \pm 0.17^{*}$ & $3.17 \pm 0.31^{* *}$ \\
D268 & $0.42 \pm 0.09$ & $0.76 \pm 0.35$ & $2.96 \pm 0.16^{*}$ & $4.12 \pm 0.44^{* *}$ \\
\hline
\end{tabular}

*Values in a same line show a significant difference between modalities

(Mann-Whitney $p=0.02$ and $p=0.03$ respectively). Between the $\mathrm{P}$ and $\mathrm{PF}$ modalities, there was no significant difference in porosity (Mann-Whitney $p=0.07$ ). Earthworms were introduced at D70. They created additional pores, but this did not significantly prevail over the action of roots. When porosity continuously decreased in $\mathrm{C}$ and WD modalities, it continuously and significantly increased with time in $\mathrm{P}$ and PF. Indeed, from D147 until the end of the experiment, porosity in PF was significantly higher than in the P modality (MannWhitney $p<0.0001$ ). As well as porosity, aggregation increased from D0 to D52 except in the control, where it stayed constant and significantly lower than in the WD, P, and PF modalities (ANOVA $p<0.0001$ ). Then the surface of aggregates slightly decreased in the P modality at D95, but still increased in PF. At D147, the surface of aggregates in PF was significantly higher than in all the other modalities (ANOVA, $p<0.0001$ ) (Table 2, b).

From D147 to D211, the surface of aggregates slightly decreased in the $\mathrm{P}$ and $\mathrm{PF}$ modalities, but porosity remained significantly higher in PF than in P (Mann-Whitney $p=0.025$ ). The surface of aggregates was closely and significantly linked to the porosity surface area (ANOVA, $p<0.0001$ ) as well as that of roots (ANOVA, $p<0.0001$ ).

\subsubsection{Synergy between the actions of roots and earthworms according to depth}

Image samples were analyzed to study the effect of soil depth and biological synergy on the evolution of quantified porosity 
parameters. Our results showed that the depth influenced the distribution of pore surface, diameter, and shape in the $\mathrm{PF}$ modality (ANOVA, $p=0.0017 ; p=0.0308 ; p=0.0287$ respectively). These parameters differed from the top to bottom of the mesocosm. Indeed, the surface, diameter, and shape of pores at the top were significantly larger than those at the bottom of the mesocosm (Turkey: $p=0.0012 ; p=0.024 ; p=$ 0.023 respectively) (Fig. $4 a$ ). In the P modality, the depth only influenced the diameter and shape of pores (ANOVA: $p=$ $0.0053 ; p=0.0093$ respectively). The surface of pores did not change according to the depth of the soil, but the pores at the top were significantly larger and more irregular than at the bottom of the mesocosm (Turkey: $p=0.024 ; p=0.023$ respectively) (Fig. 4b). At the top, the surface of pores is significantly larger in the PF than in P modality (MannWhitney: $p=0.0080$ ), yet not at the middle and the bottom of the mesocosms (Mann-Whitney: $p=0.07 ; p=1$ respectively) (Fig. 5a). Pores were significantly larger (Fig. 5b) and more irregular (Fig. 5c) in PF than in $\mathrm{P}$ at the top of the mesocosms compared to the bottom (Mann-Whitney: $p=$ $0.013 ; p=0.013$ respectively). The same trend was observed in the middle of the mesocosms (Mann-Whitney: $p=0.0018$; $p=0.0077$ respectively).

\section{Discussion}

\subsection{Effects of plant, fauna, and wetting-drying cycles on the soil structure dynamics}

Our results showed that the studied pedogenic agents differently impact the evolution of soil structure in the early stages of pedogenesis. We observed that earthworms preferentially moved along plant roots, which confirmed the synergy between the two biological agents (Zangerlé et al. 2011). Nevertheless, the ambivalent action of earthworms (creating and filling burrows) makes it possible that in some cases the soil structure (especially porosity) is improved when the root network is very dense. Therefore, instead of improving soil structure, earthworms can decrease porosity by destructing pores created by plant roots. We have shown in a recent work (Jangorzo et al. 2015) that the intensity of earthworm activity is likely to increase the surface of pores and aggregates. A comparison of these parameters between rhizosphere, drilosphere, and bulk soil confirms the positive effect of the cooperation between plant roots and earthworms demonstrated by Milleret et al. (2009). Over a very short period (from a couple of days to a week), WD cycles could have a stronger effect on the dynamics of porosity and aggregation compared to that of plant roots. It is not possible to conclude about the effect of earthworms over the short term, because, in our experiment, they were introduced 2 months after the beginning of the experiment. If the effect of WD outweighs that of $\mathrm{P}$ at
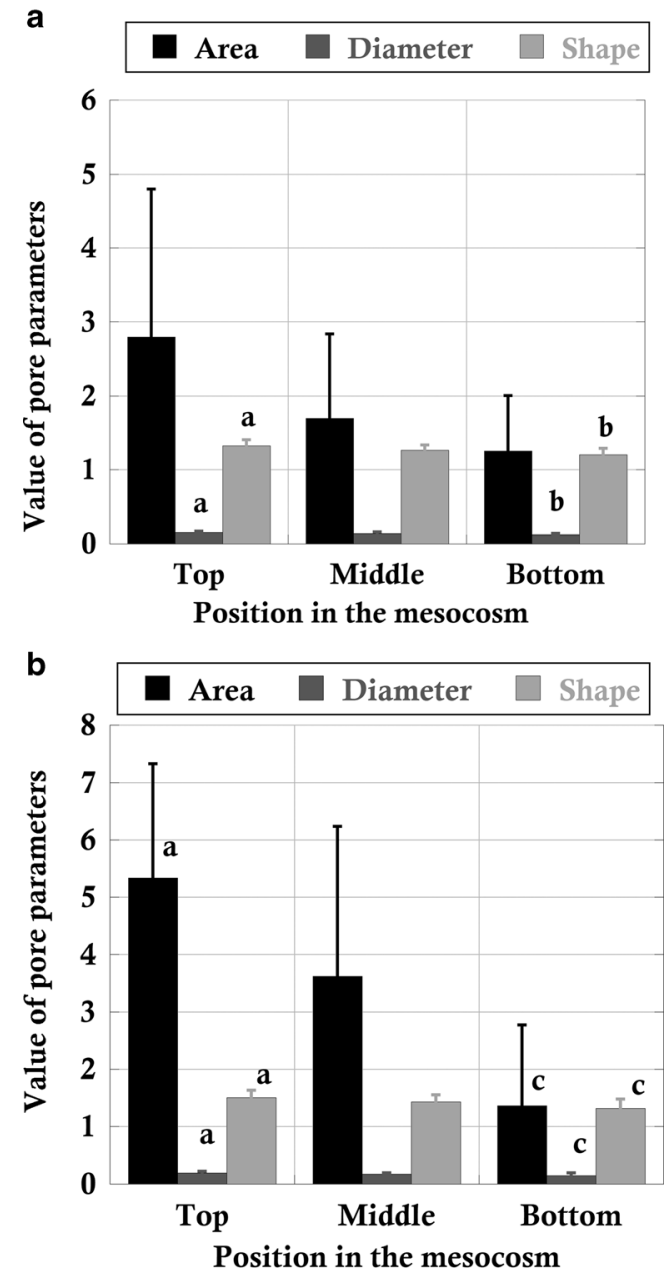

Fig. 4 Effect of the cooperation between plant roots and earthworms on soil structure according to the soil depth. a Effect of soil depth of pore parameters in PF modality. $\mathbf{b}$ Effect of soil depth of pore parameters in $\mathrm{P}$ modality. Columns followed by different letters in a different depth show a significant difference between parameters at a threshold of $5 \%$ (date were obtained from three replicates of each modality at each given date)

short term, it is because of the compacting effect of young growing roots in the rhizosphere (Dexter 1987), which decreases porosity (Bruand et al. 1996; Jangorzo et al. 2015). At intermediate and long term, in our experiment conditions, the effect of biological agents becomes significant, until they eventually outweigh that of WD. The tendency remained and became more highlighted with time. Based on these results, we propose a conceptual model, which describes the ranking of pedogenic agents in the process of aggregation over time (Fig. 6).

Aggregation agents act in a hierarchical order concerning the evolution of soil structure as well as the formation and breakdown of aggregates, as demonstrated by Tisdall and Oades (1982). Our model suggests that, the first factor intervening in the evolution of soil structure is climatic (water), as it constitutes a limiting factor for the development of organisms. If the environmental conditions are favorable to the development of plants, their roots preferentially explore existing 

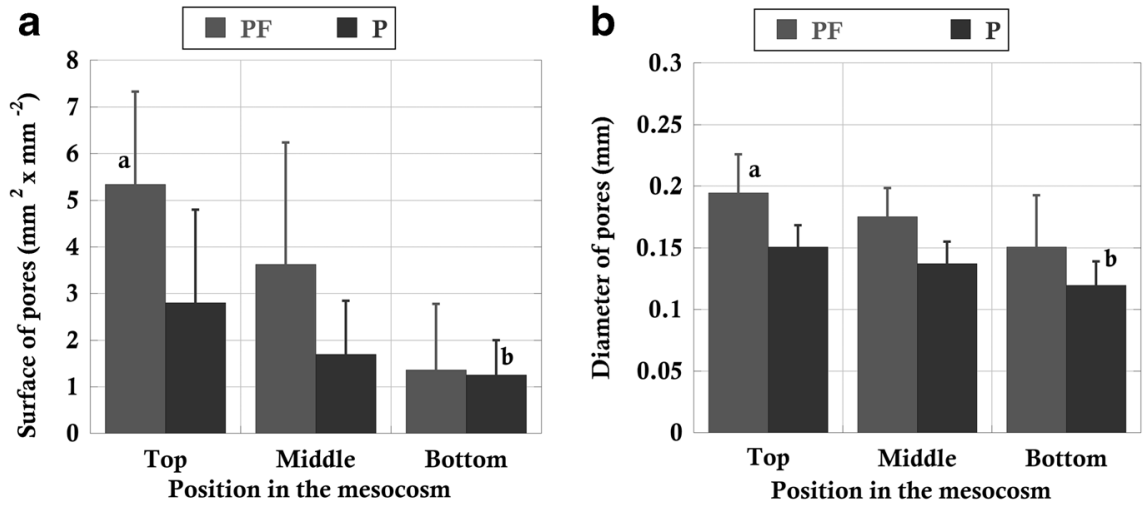

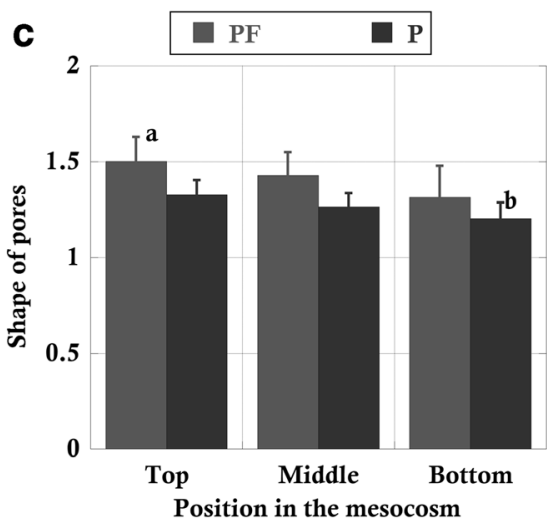

Fig. 5 Comparison of pore shapes (a), diameter (b), and surface (c) evolution between $\mathrm{P}$ and PF modalities according to soil depth. PF, plant and fauna; $\mathrm{P}$, plant. Columns followed by different letters in a

pedostructures (i.e., pores) and then contribute to the formation of additional porosity. By enmeshing soil particles, roots contribute to the formation of stable aggregates. If young roots induce a decrease in porosity, older roots induce the opposite effect, highlighting the impact of the age of the root system on soil structure. Indeed, both young and adult growing roots compressed the soil, which led to the reduction of macroporosity and indirectly of the number of aggregates (Jangorzo et al. 2015). This phenomenon was amplified when roots decayed, with all the space they had occupied being transformed into voids. The proportion of pores and aggregates created by plant roots was globally higher than that created by environmental agents over the long term. Another agent is soil fauna (earthworms), which uses the existing pedostructures created by the two previous agents to reduce the energy required for burrowing (Caro et al. 2012). For this reason, the proportion of pedostructures created by the cumulative effect of earthworms and plant roots was higher than that of plant roots, earthworms, or wetting-drying cycles separately. In natural environmental conditions, aggregation

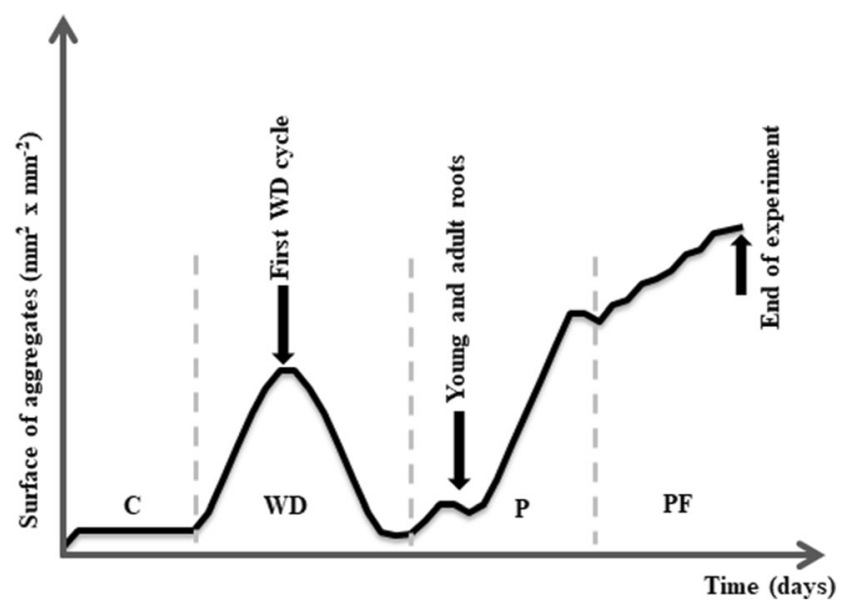

Fig. 6 Conceptual model of the dynamics of aggregation in a constructed Technosol under the influence of environmental and biological factors. C, control; WD, wetting-drying cycle; P, plant; PF, plant and fauna different depth show a significant difference between parameters at a threshold of $5 \%$ (date were obtained from three replicates of each modality at each given date)

agents mainly act simultaneously in the soil. That is why in previous studies, it has not been possible to rank the individual influence of aggregation agents. With the Soilinsight ${ }^{\circledR}$ device, we have demonstrated that with low accuracy, individually, pedogenic agents have an increasing impact in the following ascending order: wetting-drying $<$ plant $<$ fauna. In natural conditions, when wetting-drying cycles are combined with plant and earthworms, the effect remains to be studied.

\subsection{Structure soil depth dependency}

The decreasing root diameter and increasing root density with depth explain the difference in pore diameter and shape between the top and bottom of mesocosms. Indeed, at the top, large roots create large and irregular pores. At the bottom, roots are thinner, which leads to the creation of a great number of finer pores resulting in a total porosity higher than that generated by larger roots at the top. The difference in pore surface we observed at the top of mesocosms in the PF modality is then mainly due to the action of earthworms. However, we have shown that earthworms are more active at the top of the mesocosms, where they find abundant organic matter (Jangorzo et al. 2015). They created numerous, wide burrows, which contribute to increasing porosity surface area (Fig. 4e). The ecological category of earthworms used in this experiment could have an influence on the variation of pore parameters according to soil depth. However, epigeic species are known to preferentially live in the upper soil horizons, where they build more burrows. It was already surprising to find burrows as far as the bottom of the mesocosm, as if the behavior of the epigeic species used was disturbed by the experimental conditions. If we had used an endogeic species, which burrows deeply in the soil, the results may perhaps have been different as well as if the species casts at the soil surface. Moreover, we have highlighted via the video, that the juveniles that appeared preferentially at the end of the experiment stayed at the top of mesocosms and generally did not fill their 
burrows (Jangorzo et al. 2015). This may also contribute to inducing differences in pore parameters according to soil depth. As the difference in pore parameters is more significant at the top, the synergy between roots and earthworms is therefore greater at the top of mesocosms. In a recent mesocosm study dealing with plant and fauna, Deeb et al. (2017) showed that the effect of earthworms on aggregation could outweigh that of plant in particular conditions and they do not act on the same category of aggregates.

\section{Conclusions}

Based on an in situ, non-destructive, and dynamic observation of soil structure under the influence of wetting-drying cycles and plant and/or earthworm activity, we have highlighted a model of hierarchical impact of these pedogenic agents on soil structure. During the first elapsing time, wetting-drying cycles are the first to operate and the intensity of their action on soil structure is dominant. They are followed by biological factors (root development and earthworm activity) that obviously depend on suitable conditions for biological activity. Despite this ranking of agents during the first stages of pedogenesis, over the long term, biological agents have a more intense effect on soil structure than climatic ones. Furthermore, this biological effect is boosted, when several agents are present at the same time in the soil. As an extension to our results, the method of in situ observation and quantification of effects of pedogenic processes we propose could be used to study the effects of other agents (e.g., mesofauna, fungi, temperature) on soil structure. Our findings could give a substantial advance and rightness to various models describing soil formation and evolution processes. They would allow a possible extension to studies involving living organisms and requiring a dynamic and non-destructive quantification approach. These findings could also help in designing works in soil engineering, for example, deciding with accuracy which pedogenetic agents or combination of agents could be implemented to reach a goal of soil quality or of provided service.

Acknowledgements This work was funded by the French Ministry of Higher Education and Scientific Research (MENESR). The authors gratefully acknowledge Laboratoire Sols et Environnement technical staff, Alain Rakoto and Stéphane Colin, for their assistance in the realization of the Soilinsight ${ }^{\circ}$ device. The authors also acknowledge "Films d'ICI" society for the movie production.

\section{References}

Amezketa E (1999) Soil aggregate stability: a review. J Sustai Agr 14(23):83-151

Andriuzzi WS, Bolger T, Schmidt O (2013) The drilosphere concept: fine-scale incorporation of surface residue-derived $\mathrm{N}$ and $\mathrm{C}$ around natural Lumbricus terrestris burrows. Soil Biol Biochem 64:136138

Angers DA, Caron J (1998) Plant-induced changes in soil structure: processes and feedbacks. Biogeochem 42:55-72

Attou F, Bruand A (1998) Experimental study of "fragipans" formation in soils. Role of both clay dispersion and wetting-drying cycles. C R Acad Sci Ser IIA Earth Planet Sci 326:545-552

Baize D (2000) Guide des analyses en pédologie: choix, expression, présentation, interprétation. Institut National de la Recherche Agronomique, Paris

Bell CW, Asao S, Calderon F, Wolk B, Wallenstein MD (2015) Plant nitrogen uptake drives rhizosphere bacterial community assembly during plant growth. Soil Biol Biochem 85:170-182

Bottinelli N, Henry-des-Tureaux T, Hallaire V, Mathieu J, Benard Y, Duc Tran T, Jouquet P (2010) Earthworms accelerate soil porosity turnover under watering conditions. Geoderma 156:43-47

Bouché M (1975) Action de la faune sur les états de la matière organique dans les ecosystèmes. In: Kilbertus G, Reisinger O, Mourey A, Cancela da Fonseca JS (eds) Biodégradation et Humification. Pierron, Sarreguemines, France, pp 157-168

Brown GG, Barois I, Lavelle P (2000) Regulation of soil organic matter dynamics and microbial activity in the drilosphere and the role of interactions with other edaphic functional domains. Eur J Soil Biol 36:177-198

Bruand A, Cousin I, Nicoullaud B, Duval O, Bégon JC (1996) Backscattered electron scanning images of soil porosity for analyzing soil compaction around roots. Soil Sci Soc Am J 60:895-901

Caro G, Abourachid A, Decaëns T, Buono L, Mathieu J (2012) Is earthworms' dispersal facilitated by the ecosystem engineering activities of conspecifics? Biol Fertil Soils 48:961-965

Deeb M, Desjardins T, Podwojewski P, Pando A, Blouin M, Lerch TZ (2017) Interactive effects of compost, plants and earthworms on the aggregations of constructed Technosols. Geoderma 305:305-313

Denef K, Six J, Bossuyt H, Frey SD, Elliott ET, Merckx R, Paustian K (2001) Influence of dry-wet cycles on the interrelationship between aggregate, particulate organic matter, and microbial community dynamics. Soil Biol Biochem 33:1599-1611

Dexter AR (1987) Compression of soil around roots. Plant Soil 97:401406

Ernst G, Müller A, Göhler H, Emmerling C (2008) C and N turnover of fermented residues from biogas plants in soil in the presence of three different earthworm species (Lumbricus terrestris, Aporrectodea longa, Aporrectodea caliginosa). Soil Biol Biochem 40:1413-1420

Fründ HC, Butt K, Capowiez Y, Eisenhauer N, Emmerling C, Ernst G, Potthoff M, Schädler M, Schrader S (2010) Using earthworms as model organisms in the laboratory: recommendations for experimental implementations. Pedobiologia 53:119-125

Hawkes CV, DeAngelis KM, Firestone MK (2007) 1 - Root interactions with soil microbial communities and processes. In: Whitbeck ZGCL.(ed) The Rhizosphere. Academic Press, Burlington, pp 1-29

Haynes RJ, Beare MH (1997) Influence of six crop species on aggregate stability and some labile organic matter fractions. Soil Biol Biochem 29:1647-1653

Hinsinger P, Bengough AG, Vetterlein D, Young IM (2009) Rhizosphere: biophysics, biogeochemistry and ecological relevance. Plant and Soil 321(1-2):117-152

Huhta V, Wright DH, Coleman DC (1989) Characteristics of defaunated soil. I: a comparison of three techniques applied to two different forest soils Pedobiologica 33(6):417-426

IUSS Working Group WRB, World Reference Base for soil Resources (2006) A framework for international classification, correlation and communication: 2nd edn. World Soil Resources Reports, 132, p 145

Jangorzo NS, Watteau F, Schwartz C (2013) Evolution of the pore structure of constructed Technosols during early pedogenesis quantified by image analysis. Geoderma 207-208:180-192 
Jangorzo NS, Schwartz C, Watteau F (2014) Image analysis of soil thin sections for a non-destructive quantification of aggregation in the early stages of pedogenesis. Eur J Soil Sci 65:485-498

Jangorzo NS, Watteau F, Hajos D, Schwartz C (2015) Nondestructive monitoring of the effect of biological activity on the pedogenesis of a Technosol. J Soils Sediments 15(8):1705-1715

Lavelle P (1988) Earthworm activities and the soil system. Biol Fertility of Soils 6:237-251

Leguédois S, Séré G, Auclerc A, Cortet J, Huot H, Ouvrard S, Watteau F, Schwartz C, Morel JL (2016) Modelling pedogenesis of Technosols. Geoderma 262:199-212

Lowe CN, Butt KR (2005) Culture techniques for soil dwelling earthworms: a review. Pedobiologia 49:401-413

Mathieu C, Pieltain F, Asseline J, Chossat, JC, Valentin CH (1998) Analyse physique des sols: méthodes choisies. TEC \& DOC, Lassay-les-Chateaux

Milleret R, Le Bayon RC, Gobat JM (2009) Root, mycorrhiza and earthworm interactions: their effects on soil structuring processes, plant and soil nutrient concentration and plant biomass. Plant Soil 316:1-12

Niewczas J, Witkowka-Walczak B (2005) The soil aggregates stability index (ASI) and its extreme values. Soil Till Res 80:69-78

Pey B (2010) Diversité et rôle fonctionnel de la faune du sol dans un sol construit en milieu industriel: contribution à la modélisation de l'évolution d'un Technosol. Thèse de Doctorat de l'INPL, Nancy, France

Pey B, Cortet J, Capowiez Y, Nahmani J, Watteau F, Schwartz C (2014) Technosol composition affects Lumbricus terrestris surface cast composition and production. Ecol Eng 67:238-247
Pey B, Cortet J, Watteau F, Cheynier K, Schwartz C (2013) Structure of earthworm burrows related to organic matter of a constructed Technosol. Geoderma 202-203:103-111

Séré G, Schwartz C, Ouvrard S, Renat JC, Watteau F, Villemin G, Morel JL (2010) Early pedogenic evolution of constructed Technosols. J Soils Sediments 10:1246-1254

Séré G, Schwartz C, Ouvrard S, Sauvage C, Renat JC, Morel JL (2008) Soil construction: a step for ecological reclamation of derelict lands. J Soils Sediments 8:130-136

Singer MJ (1992) Stability of synthetic sand-clay aggregates after wetting and drying cycles. In. Bronick and Lal (2005). Soil structure and management: a review. Soil Sci Soc Am J 56:1843-1848

Six J, Bossuyt H, Degryze S, Denef K (2004) A history of research on the link between (micro) aggregates, soil biota and soil organic matter dynamics. Soil Till Res 79:7-31

Smetak KM, Johnson-Maynard JL, Lloyd JE (2007) Earthworm population density and diversity in different-aged urban systems. Appl Soil Ecol 37:161-168

Taina IA, Heck RJ, Elliot TR (2008) Application of X-ray computed tomography to soil science: a literature review. Can J Soil Sci 88: $1-20$

Tisdall JM, Oades JM (1982) Organic matter and water stable-aggregates in soils. J Soil Sci 33(2):141-163

Zangerlé A, Pando A, Lavelle P (2011) Do earthworms and roots cooperate to build soil macroaggregates? A microcosm experiment. Geoderma 167-168:303-309 